\title{
The Effect of Option Trading at the DTB on the Underlying Stocks' Return Variance ${ }^{1}$
}

\author{
Burkhard Heer, Mark Trede and Mark Wahrenburg \\ Seminar für Staatswissenschaften and Seminar für Wirtschafts- und Sozialstatistik, \\ Universität zu Köln, Albertus-Magnus-Platz, D-50923 Köln, Germany
}

\begin{abstract}
The effects of option trading at the DTB on the variance of the underlying stocks are examined. We use a new distribution free test being based on the empirical distribution functions. The evidence indicates that stock return variance increased after the introduction of the DTB. This effect can be partly explained by the strong increase in trading volume for option listed stocks. Our results stand in stark contrast to prior studies of both American and European financial markets.
\end{abstract}

Keywords: Stock market volatility, option trading, Deutsche Terminbörse, nonparametric tests, stochastic dominance.

JEL Classification System-Numbers: G14, C14

\section{Introduction}

The impact of derivatives trading on stock market volatility is an ongoing debate. Although a large body of empirical studies finds either a decrease or at least no significant increase in volatility after option introduction, concerns about increasing volatility due to option trading do not vanish. The German central bank, for instance, warns that derivatives trading in conjunction with modern arbitrage and communication technology may increase price changes in the underlying spot market (Deutsche Bundesbank, 1993, p. 61). In a similar manner, Stein (1987) argues that derivative markets serve as a conduit for new speculators into the spot market that may destabilize prices. These arguments found theoretical support by Grossman (1988) who argues that market volatility increases when more traders follow price insensitive trading strategies and the market cannot observe the informationless nature of these trades. Since derivatives trading causes transactions in the underlying stock from arbitrage activities or portfolio insurance operations it may thus increase stock return

\footnotetext{
1 We thank two anonymous referees, F. Schmid, C, C. von Weizsäcker, Jürgen Wolters and the participants at the 7th World Congress of the Econometric Society (Tokyo), the 1995 Annual Meeting of the Verein für Socialpolitik (Linz) and the Economic Research Seminar of the University of Cologne for valuable comments.
} 
volatility. Another popular argument claims that through small margin requirements option markets allow speculators to take highly leveraged stock positions which in turn increases market volatility (Hardouvelis, 1988). Finally, the well established empirical association between trading volume and volatility (Karpoff, 1987) may explain a rise in stock volatility if stock market trading activity increases after option introduction.

The opening of the German Futures and Option exchange DTB (Deutsche Terminbörse) in 1990 created a new opportunity to test the increasing volatility hypothesis. Two reasons make the DTB a particularly interesting object of research. First, the DTB quickly attracted a large amount of trading volume and became by far the largest European option exchange in terms of option turnover (DTB - Deutsche Terminbörse GmbH, 1993, p. 14). If option trading has an impact on market volatility the DTB can thus be expected to have a particularly pronounced effect. Second, the DTB started operation at a point of time when phenomena like portfolio insurance and automated arbitrage execution had become increasingly common. In contrast, existing studies of USoption listings cover at most the period between 1973 and 1986, while studies of other financial markets do not extend beyond 1989. Prior to the opening of the DTB a small amount of stock option trading took place at the Frankfurt Stock Exchange. However, trading volume was so limited that it probably did not affect stock markets. For example, the amount of outstanding call (put) options at the DTB for the end of 1990 was already 34 (117) times higher than the respective 1989 figures for the stock exchange based option trading (Deutsche Bundesbank, Kapitalmarktstatistik).

The paper is organized as follows: Section 2 reviews existing empirical evidence on the effect of option listing on stock return variance; section 3 examines the data set and the applied methodology; section 4 reports our test results; and section 5 summarizes the findings and contains some concluding remarks.

\section{Review of Empirical Studies}

Most of the empirical studies in stock price behavior after option listing have found evidence that the introduction of options reduces the return volatility of the underlying securities while the systematic risk remains unchanged. Empirical investigations are mainly conducted for the CBOE (Chicago Board Options Exchange) and the AMEX (American Stock Exchange). Early studies include Trennepohl and Dukes (1979), Klemkosky and Maness (1980). Whiteside, Dukes and Dunne (1983) and Hayes and Tennenbaum (1979). Klemkosky and Maness (1980) find only little evidence for a change in both systematic risk as measured by the firms' beta and total risk as measured by the variance of the returns. The results of Trennepohl and Dukes (1979) and Whiteside, Dukes and Dunne 
(1983), however, indicate a decline in the betas of the optioned securities. Hayes and Tennenbaum (1979) conclude that listed options lower the volatility of the underlying stocks. More recent studies of Bansal, Pruitt and Wei (1989) and Detemple and Jorion (1990) suggest that option listing leads to decreases in total but not systematic risk of the underlying securities in the American markets.

Ma and Rao (1986) examine the differential characteristics of stocks experiencing increased volatility after option listing and those experiencing decreased volatility. They apply multivariate linear discriminant analysis on these two groups. Stocks with low return, high risk, low trading volume and low growth potential are more likely to be stabilized by option trading. Similarly, Ma and Rao (1988) conclude that there is no uniform impact of option trading on the underlying securities. Empirical tests support the hypothesis that volatile stocks become more stable after listing while stable securities become more volatile. As an explanation, $\mathrm{Ma}$ and $\mathrm{Rao}$ contend that the listing of options attracts different kinds of additional traders in these two cases. Option listing might lead to increased speculation with stable stocks and, consequently, increase volatility, whereas traders might hedge in options with volatile stocks and, therefore, returns stabilize after listing.

Conrad (1989) and Skinner (1989) analyze daily return data of stocks with options introduced at the CBOE and AMEX. Conrad (1989) estimates the market model over a period of 200 days outside the event window which comprises 30 days prior and after the listing of the option. She notices a significant decline in volatility. However, applying a simple paired t-test she finds no evidence that the systematic risk as measured by the beta of the market model changes. Similarly, using sampling intervals of 100, 250 and 500 trading days on either side of the event, Skinner (1989) concludes that the return variance declines, and that this decline is only partly explainable by a contemporaneous change in market volatility. Again, there is no change in the firms' beta around the time of option listing. Skinner tests two possible explanations for the decline in variance: on the one hand changes in trading activity and, on the other hand, changes in trading noise. Empirically, there exists a well documented positive correlation between stock price changes and trading volume (Harris, 1989, Karpoff, 1987, and Schwert, 1989). Consistent with this evidence, Skinner (1989) finds that the decrease of stock return volatility after option introduction was significant only for those stocks that experienced volume changes below the sample median value. Analyzing the autocorrelation structure of stock returns before and after listing of the options he finds little support for the hypothesis that the changes in variance are related to changes in trading noise.

Using both a parametric test (a variance ratio test) and a non-parametric test (a median test) Damodaran and Lim (1991) observe an overall decline in variance in the daily returns of the underlying stock after listing of options at the CBOE and the AMEX between 1973 and 1986. Furthermore, Damodaran and Lim test potential explanations of this phenomenon, and, for this reason, decompose the observed return variance into three components: i) the intrinsic 
variance, which is attributable to the volatility of the underlying business, ii) a price adjustment component and iii) a noise term which results from information noise and the bid-ask spread. While the first component remains unaffected, prices adjust more quickly following the listing of options and the noise component declines as well. Damodaran and Lim explain the reduction in noise by a decline of the bid-ask spread which is caused by increased competition from market makers on the option market and increased institutional interest in the stocks after listing.

Empirical Studies of other option markets are in accordance with the results found in US option markets. For the Canadian markets, Elfakhani and Chaudhury (1995) find that stock return volatility, after controlling for changes in market volatility, declines following option listing. Only for the subperiod 198085 , they find a slight but not significant increase in return volatility. Nölkel (1990) as well as Stucki and Wasserfallen (1994) also find evidence for a decline in volatility at the Swiss Option exchange market (SOFFEX) after option introduction. Schlag (1991) examines the German option market, the DTB. Using weekly returns between January 1989 and October 1990 he finds no support for the hypothesis that volatility increases after option listing. However, he concedes that results are inconclusive due to the short observation interval. The DTB started trading in January 1990 and option trading volume only increased significantly after the introduction of the DAX-Future in November 1990.

\section{Data and Methodology}

When the DTB opened on 26 January 1990 options on just 14 stocks were introduced. These stocks were: Allianz, BASF, Bayer, BMW, Commerzbank, Daimler, Deutsche Bank, Dresdner Bank, Hoechst, Mannesmann, Siemens, Thyssen, VEBA, and Volkswagen. Since 24 September 1990 options on RWE stocks are also traded. These 15 optioned stocks form our basic sample.

For comparison a control sample of non-optioned stocks is drawn. Since only renowned stocks with very liquid markets were admitted for option listing at the DTB we allowed only stocks being traded in the so called continuous trade segment of the Frankfurt stock exchange to enter the control sample. Further, the sample exhibits approximately the same size and industry structure as the basic DTB sample. These stocks are Bayrische Hypothekenbank, Trinkaus \& Burkhard, Rabobank, Schering, Porsche, Vereins- und Westbank, BHFBank, Rheinmetall, Hochtief, Preussag, KHD, Deutsche Hypothekenbank, Henkel, MAN, Rheinelektra, Degussa, and VEW. Options on Bayrische Hypothekenbank were not launched until January 1994 and therefore Bayrische Hypothekenbank does not belong to the DTB sample.

We used daily spot prices from 2 March 1987 up to 31 August 1993 for all stocks. Prices are adjusted for dividend payments and capital increases. 
Define the returns as $r_{t}=\log \left(p_{t} / p_{t-1}\right)$. Applying an Andersen-Darling test for normality of the returns reveals that their distribution is significantly nonnormal. This is a well-known phenomenon for daily returns. However, even the distribution of weekly returns is significantly non-normal in almost all cases. Further, most returns are first and/or second order autocorrelated. This is in accordance with the results of Bauer, Nieuwland and Verschoor (1994).

These findings suggest that standard methods such as the ordinary F-test for differences in variances are not applicable. However, instead of using the F-test adapted to certain kinds of nonnormality (Runde, 1993) we will draw on nonparametric methods as the true distribution of the returns is unknown. Commonly the change in volatility is measured by the variance ratios

$$
T(d)=\frac{\sigma_{\text {post }}^{2}\left(t_{0}+11, t_{0}+10+d\right)}{\sigma_{\text {pre }}^{2}\left(t_{0}-10-d, t_{0}-11\right)}
$$

where $\sigma_{\text {post }}^{2}(\cdot, \cdot)=\frac{1}{d} \sum_{t=t_{0}+11}^{t_{0}+10+d}\left(r_{t}-\frac{1}{d} \sum_{t=t_{0}+11}^{t_{0}+10+d} r_{t}\right)^{2}$ is the variance of returns of some stock in the period from $t_{0}+11$ up $t_{0}+10+d$ with $t_{0}$ denoting the day of option introduction; $\sigma_{p r e}^{2}$ is defined likewise for the variance before options were introduced. Note that $\sigma_{p o s t}^{2}$ and $\sigma_{p r e}^{2}$ (and thus $T(d)$ ) are random variables. Ten observations immediately preceding and following the introduction were deleted to eliminate any introductory price effects. The implementation of $d$ into (1) allows the observation period to vary so as to determine the impact of time.

To find out whether the volatility of optioned stocks has increased after option introduction we have to look at $T_{D T B}(d) . T_{D T B}(d)>1$ indicates an increase in volatility for optioned stocks. However, volatility might have also gone up for the whole market in which case $T_{D T B}(d)>1$ does not necessarily mean that volatility has been aggravated by option introduction at the DTB. Rather, one should compare the distribution functions of the variance ratio of optioned stocks $\left(F_{T_{D T B}}(t)\right)$ and unoptioned stocks $\left(F_{T_{N O S}}(t)\right)$ both of which are, of course, unknown. Different variants of this method have become the standard approach in the literature (see e.g., Skinner, 1989, Damodaran and Lim, 1991, Elfakhani and Chaudhury, 1995, Stucki and Wasserfallen, 1994).

Following this literature we calculated the variance ratio for each stock of the DTB sample $\left(t_{D T B, i}(d), i=1, \ldots, 15\right)$ and the comparison sample $\left(t_{N O N, i}(d)\right.$, $i=1, \ldots, 17)$. As usual, these values are regarded as realizations of randomly drawn samples from optioned and unoptioned stocks. In other words, the observations $T_{D T B, i}(d)$ and $T_{N O N, i}(d)$ are the (non-random) empirical counterparts of the (random) sample values $T_{D T B, i}$ and $T_{N O N, i}$, respectively. Table 1 displays the empirical variance ratios for both the DTB sample and the comparison sample. $^{2}$

2 We also tried to deflate the returns by the standard deviation of the FAZ index to allow for changes in market returns as suggested by Skinner (1989). However, this did not alter our findings greatly. 
Table 1. Empirical variance ratios for the DTB sample and the comparison sample

\begin{tabular}{|c|c|c|c|c|c|}
\hline \multicolumn{6}{|c|}{ DTB Sample: $t_{D T B, i}(d)$} \\
\hline Stock & $i$ & $d=100$ & $d=250$ & $d=500$ & $d=700$ \\
\hline VEBA & 1 & 0.28684 & 0.98567 & 1.11934 & 0.81172 \\
\hline Thyssen & 2 & 0.51482 & 1.39199 & 1.31917 & 0.99636 \\
\hline Commerzbank & 3 & 0.58793 & 1.24950 & 1.22431 & 0.86064 \\
\hline Siemens & 4 & 0.45285 & 1.33352 & 0.91506 & 0.57581 \\
\hline RWE & 5 & 1.05770 & 0.53982 & 0.49214 & 0.45628 \\
\hline Deutsche Bank & 6 & 0.40276 & 1.07891 & 0.84017 & 0.48970 \\
\hline Mannesmann & 7 & 0.29563 & 0.79776 & 0.90501 & 0.71450 \\
\hline Dresdner Bank & 8 & 0.48689 & 1.31106 & 0.98613 & 0.61704 \\
\hline Allianz & 9 & 0.62278 & 1.71997 & 1.37710 & 0.52529 \\
\hline BASF & 10 & 0.72623 & 1.78112 & 1.58475 & 1.01218 \\
\hline Volkswagen & 11 & 0.34255 & 1.17974 & 1.27908 & 0.84408 \\
\hline Bayer & 12 & 0.74598 & 2.09955 & 1.62672 & 0.86865 \\
\hline Hoechst & 13 & 0.88065 & 2.06712 & 1.99475 & 1.20088 \\
\hline Daimler & 14 & 0.33768 & 1.11673 & 0.98594 & 0.59675 \\
\hline BMW & 15 & 0.46756 & 1.40590 & 1.47514 & 0.75150 \\
\hline \multicolumn{6}{|c|}{ Comparison Sample: $t_{N O N, i}(d)$} \\
\hline Stock & $i$ & $d=100$ & $d=250$ & $d=500$ & $d=700$ \\
\hline BayHypBank & 1 & 0.41356 & 0.87588 & 0.99320 & 0.58313 \\
\hline Trinkaus \& Burkhard & 2 & 0.28654 & 0.73496 & 0.59353 & 0.32597 \\
\hline Rabobank & 3 & 2.22564 & 1.27404 & 0.79290 & 0.37319 \\
\hline Schering & 4 & 0.51043 & 1.16895 & 0.89520 & 0.45637 \\
\hline Prosche & 5 & 0.62447 & 1.50986 & 1.32058 & 0.77570 \\
\hline Vereins- \& Westbank & 6 & 0.21453 & 0.53527 & 0.69904 & 0.54379 \\
\hline BHF-Bank & 7 & 0.99619 & 1.52853 & 1.02935 & 0.62989 \\
\hline Rheinmetall & 8 & 0.25318 & 0.66725 & 0.94556 & 0.66064 \\
\hline Hochtief & 9 & 0.79364 & 1.10058 & 1.23248 & 0.98232 \\
\hline Preussag & 10 & 0.61181 & 1.12813 & 0.87353 & 0.60344 \\
\hline KHD & 11 & 0.26474 & 0.77555 & 0.90372 & 0.55997 \\
\hline Deutsche HypBank & 12 & 1.80891 & 0.71272 & 0.74596 & 0.62529 \\
\hline Henkel & 13 & 0.25361 & 0.69827 & 0.79077 & 0.52053 \\
\hline MAN & 14 & 0.19707 & 0.60648 & 0.76226 & 0.54654 \\
\hline Rheinelektra & 15 & 0.54561 & 2.31993 & 1.25334 & 1.00793 \\
\hline Degussa & 16 & 0.28316 & 0.84962 & 1.01390 & 0.67594 \\
\hline VEW & 17 & 0.48537 & 0.56773 & 0.81407 & 0.67175 \\
\hline
\end{tabular}

Remark: The DTB sample is sorted in ascending order by change in trading volume between 6 months before options introduction and 6 months after.

From previous studies we suspect $T_{N O N}$ to stochastically dominate $T_{D T B}$, i.e., the probability of $T_{N O N}$ to fall short of a certain value is expected to be smaller than for $T_{D T B}$. To test this hypothesis we apply traditional tests of stochastic dominance such as the Wilcoxon-Mann-Whitney test as well as a more powerful distribution free test suggested by Schmid and Trede (1996). The rationale for the latter test is as follows: If $T_{N O N}$ does indeed stochastically 
dominate $T_{D T B}$ then the theoretical curve $\left(F_{T_{N O N}}(t), F_{T_{D T B}}(t)\right), t \in \mathbb{R}$, is always above the diagonal of a unit square (see figure 1 for a constructed example). Notice that this curve is but the usual p-p-plot (probability plot) of the two distribution functions.

A natural non-parametric estimator of the unknown distribution function is the empirical distribution function. Let $\hat{F}_{T_{D T B}}(t)$ and $\hat{F}_{T_{\text {Nas }}}(t)$ denote the empirical distribution functions of $T_{D T B}$ and $T_{N O N}$, respectively. Then even if the true curve $\left(F_{T_{\text {Nov }}}(t), F_{T_{D T B}}(t)\right)$ lies entirely above the diagonal the estimated curve $\left(\hat{F}_{T_{N O K}}(t), \hat{F}_{T_{D T B}}(t)\right)$ may nevertheless divert into the area below the diagonal - due to random fluctuations. Yet if the estimated curve diverts "too much" we should reject the null hypothesis of stochastic dominance.

An obvious measure of how far the curve extends below the diagonal is the area between that part of the curve which lies below the diagonal and the diagonal itself (see the shaded area in figure 1). This area can easily be computed. The test statistic to be used is just the observed area normalized by the factor $(n m /(n+m))^{0.5}$ where $n$ and $m$ are the number of observations of the two distributions. Since the test statistic depends on the ranks of the observations only, we can compute exact critical values by complete enumeration for any $n$ and $m$ and the desired level of significance. If the test statistic is larger than the critical value we should reject the null. Regarding power, the p-p-test turns out to have more power than the conventional tests if the curve intersects the diagonal at the begining and/or the end. It is always superior to the WilcoxonMann-Whitney test; for rather small deviations from the null hypothesis it also performs better than the Kolmogorov-Smirnov test. For more details about the test theory see Schmid and Trede (1996).

Many empirical studies consider the random drawings from the optioned and unoptioned stocks, respectively, as independent. This assumption of course facilitates the statistical testing procedure. However, it is not reasonable to

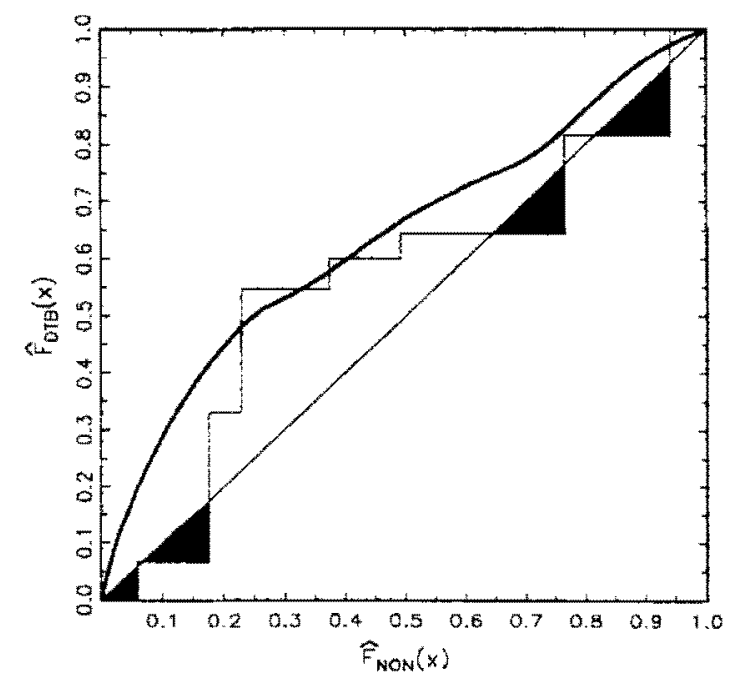

Fig. 1. Constructed example of a p-p-plot of true distribution functions (thick line) and empirical distribution functions (thin line) 
presuppose global independence within and between the samples as market shocks on the volatility will, in general, exert influence on all stocks alike. Yet the test statistic of the p-p-test as defined above is robust against certain kinds of dependencies. In particular, consider the case where the market impact on the volatility is of the multiplicative form

$$
\begin{aligned}
& \sigma_{\text {pre }, \mathrm{DTB}, i}^{2}=\tilde{\sigma}_{\text {pre }, \mathrm{DTB}, i}^{2} Z_{\text {pre }} \\
& \sigma_{\text {pre }, \text { NON }, i}^{2}=\tilde{\sigma}_{\text {pre }, \text { NoN }, i}^{2} Z_{\text {pre }} \\
& \sigma_{\text {post }, \mathrm{DTB}, i}^{2}=\tilde{\sigma}_{\text {post }, \mathrm{DTB}, i}^{2} Z_{\text {post }} \\
& \sigma_{\text {post }, \mathrm{NON}, i}^{2}=\tilde{\sigma}_{\text {post }, \text { NON }, i}^{2} Z_{\text {post }}
\end{aligned}
$$

where $\tilde{\sigma}_{p r e, D T B, i}^{2}, \tilde{\sigma}_{\text {post }, D T B, i}^{2}, \tilde{\sigma}_{p r e, N O N, i}^{2}$, and $\tilde{\sigma}_{p o s t, N O N, i}^{2}$ are i.i.d. and independent of the (strictly positive) random shocks $Z_{p r e}$ and $Z_{p o s t}$. In this setting the actual volatilities (on the left hand side) are not independent, neither within nor between the two groups. Therefore the sample values of the variance ratio,

$$
T_{D T B, i}=\frac{\sigma_{D T B, p o s t, i}^{2}}{\sigma_{D T B, p r e, i}^{2}}=\frac{\tilde{\sigma}_{D T B, p o s t, i}^{2}}{\tilde{\sigma}_{D T B, p r e, i}^{2}} \frac{Z_{\text {post }}}{Z_{\text {pre }}}
$$

and

$$
T_{N O N, i}=\frac{\sigma_{N O N, \text { post }, i}^{2}}{\sigma_{N O N, \text { pre }, i}^{2}}=\frac{\tilde{\sigma}_{N O N, p o s t, i}^{2}}{\tilde{\sigma}_{N O N, p r e, i}^{2}} \frac{Z_{\text {post }}}{Z_{\text {pre }}},
$$

are also dependent due to the common market shock $Z=Z_{\text {posi }} / Z_{\text {pre }}$. However, it is easily seen that the test statistic of the distribution free p-p-test and its distribution do not change. The same holds true for the traditional tests of stochastic dominance, a fact which is often neglected in the statistical literature.

\section{Results}

Variance ratios have been computed for both the DTB sample and the comparison sample (see table 1). To allow for possible time effects the parameter $d$ varies. Table 2 displays some descriptive statistics of the distribution of the test statistic for both samples. The mean, median and standard deviation are given for various lengths of the observation period ranging from \pm 100 days up to \pm 700 days.

The results shown in table 2 are in stark contrast to previous studies. Apart from an observation period of \pm 100 days we find that on average volatility increased more for optioned stocks. The same holds true for the median. Schlag's finding of a short term variance decline for DTB stocks has thus reversed over longer time periods. Neglecting the non-normality one could do a t-test for differences in mean between the two samples. This turns out to be significant at the $5 \%$ level for all but the first $( \pm 100)$ row. 
Table 2. Mean and median of test statistic

\begin{tabular}{|ll|ll|}
\hline$d$ & & DTB sample & non-DTB \\
\hline 100 & Mean & 0.54726 & 0.63344 \\
& Median & 0.48689 & 0.48537 \\
& Std. dev. & 0.22494 & 0.57017 \\
\hline \multirow{2}{*}{250} & Mean & 1.33722 & 1.00316 \\
& Median & 1.31106 & 0.84962 \\
& Std. dev. & 0.43623 & 0.46180 \\
\hline \multirow{2}{*}{500} & Mean & 1.20832 & 0.92114 \\
& Median & 1.22431 & 0.89520 \\
& Std. dev. & 0.37660 & 0.20213 \\
\hline 700 & Mean & 0.75476 & 0.62014 \\
& Median & 0.75150 & 0.60344 \\
& Std. dev. & 0.21525 & 0.17925 \\
\hline
\end{tabular}

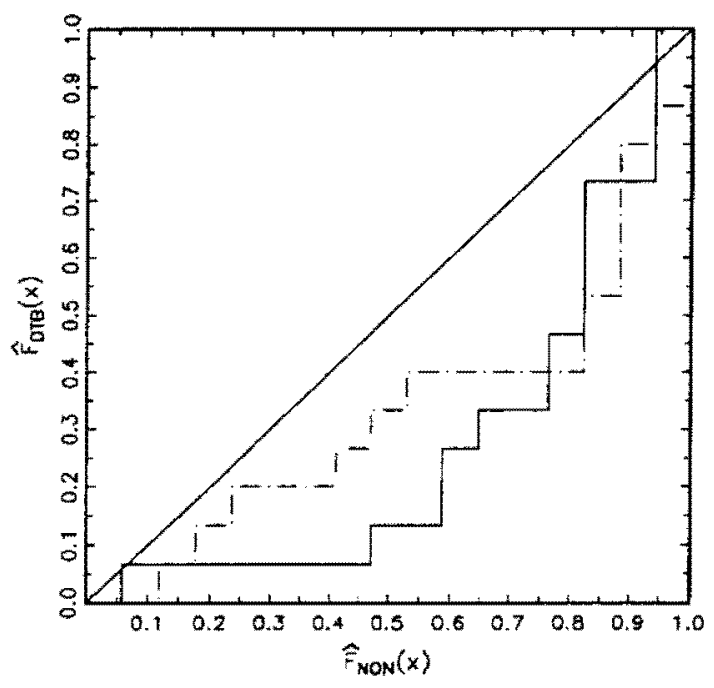

Fig. 2. p-p-plot of the empirical distribution functions

Concerning stochastic dominance figure 2 depicts the p-p-plots for $d=250$ (solid line) and $d=700$ (dashed line). The other curves not shown in this figure look similar to the latter one. Again, the results do not confirm the traditional view. Instead of $T_{D T B}$ being dominated by $T_{N O N}$ the situation is rather reversed. Option trading apparently increases volatility. Subjecting the hypothesis $H_{0}$ : ' $T_{N O N}$ dominates $T_{D T B}$ ' formally to the test presented in the last section we find that the hypothesis is rejected for observation periods above \pm 100 ; table 3 gives values of the test statistic for all observation periods. ${ }^{3}$

3 Applying a Wilcoxon test yields similar results whereas the Kolmogorov-Smirnov test is significant only at a $10 \%$ level for $d=250$ and $d=500$. The test results can be obtained from the authors on request. 
Table 3. Test statistic values of the test for stochastic dominance of the DTB sample against the comparison sample

\begin{tabular}{|c||llll|}
\hline Observation period $d$ & 100 & 250 & 500 & 700 \\
\hline \hline $\begin{array}{c}\text { whole DTB sample } \\
\text { (15 stocks) }\end{array}$ & 0.2133 & $0.5661^{* *}$ & $0.6546^{* * *}$ & $0.3875^{*}$ \\
$\begin{array}{c}\text { below median change } \\
\text { in volume (8 stocks) } \\
\text { above median change } \\
\text { in volume (7 stocks) }\end{array}$ & 0.1415 & 0.2144 & 0.1629 & 0.1179 \\
\hline
\end{tabular}

Remark: ***,*** indicate singificance at $10 \%, 5 \%, 1 \%$ level, resp. Tables of the critical values of the test statistic and a description of how to compute them are given in Schmid and Trede (1996).

In order to assess the impact of trading volume on the change in volatility we split the DTB sample. The first half contains DTB stocks with less than the median change in trading volume (these are the first eight stocks shown in table 1). The other half consists of the DTB stocks experiencing more than the median increase in trading volume. These two samples have seperately been subjected to the p-p-test against the non-DTB sample. The results are also given in table 3.

The results are rather clear-cut. The null hypothesis that volatility decreases after option introduction can be firmly rejected for the full sample and the sample with above median trading volume. However, two caveats need to be mentioned. First, although the tests provide significant evidence that $F_{\text {NON }}(t)$ does not stochastically dominate $F_{D T B}(t)$ one must be careful not to conclude that $F_{D T B}(t)$ dominates $F_{N O N}(t)$. As the empirical distribution functions sometimes cross at very low and very high levels of volatility it is not possible to positively establish stochastic dominance. Second, as only 15 stocks are optioned at the DTB for a sufficiently long period the data basis is rather weak. Moreover, 14 of the options have been introduced at the same point of time. The data might be dependent in some way which our test is not robust against. Therefore, the results presented in this paper have to be interpreted rather as an event study. The statistical inference is to be taken with care.

Nevertheless, the tests prove wrong the conventional view that options tend to dampen volatility, at least for the German stock market. They give strong evidence supporting the opposite view. Further, the distinction between stocks experiencing large increases in trading volume and those experiencing small changes reveals noticable differences. The more the volume increases the more volatility tends to increase as well.

In accordance with these observations for the split DTB sample one could try to explain the overall increase of the return variance of the DTB stocks in relation to the non-DTB sample by a corresponding relative change in trading volume. Since option listed stocks account for a large share of overall stock trading activity in Germany we compared their trading activity with the broad monthly measure of stock trading activity on all German stock exchanges 
Table 4. Ratio of stock trading volume of 5 months before and after option listing for optioned stocks and overall market

\begin{tabular}{|l|l|}
\hline Mean & 2.01 \\
Median & 1.98 \\
Min & 1.30 \\
Max & 3.15 \\
Std. dev. & 0.54 \\
Overall market & 1.35 \\
\hline
\end{tabular}

Source: Deutsche Börse AG, Deutsche Bundesbank, Kapitalmarktstatistik

published by the German central bank. Table 4 gives the ratio of trading volume 5 months before and after January 1990, when the DTB started operations. ${ }^{4}$ The data show a strong increase in trading volume for option listed stocks. Trading volume of option listed stocks, on average, doubled after introduction of the DTB while the overall stock market trading volume rose only by one third.

The experience of trading volume changes again stands in contrast to findings in the US market which show either a decrease (Damodoran and Lim, 1989) or only a slight increase in trading volume (Skinner, 1989, and Bansal, Pruitt and Wei, 1989).

\section{Summary and Conclusion}

In contrast to the experience from US markets, German stock returns became more volatile after introduction of options at the DTB. The documented change of return variance is also of considerably larger size than those documented for the US market. The median variance of option listed stocks rose by $34 \%$ over a 250 day interval while at the same time it declined by $15 \%$ for a control sample of non DTB stocks. Thus the relative increase of return variance is close to $50 \%$. We can firmly reject the hypothesis that optioned stocks became less volatile after introduction of the DTB.

We find volatility increase to be associated with a strong increase in trading volume. Trading volume on average doubled from 5 months before to 5 months after option introduction and the variance increase is more pronounced for stocks that experienced above median trading volume increases. Thus one explanatory factor of the volatility increase after introduction of the DTB seems to be the impact of the DTB on trading volume. Although the strong increase of trading volume is puzzling given the US experience it may be explained at

4 The RWE stock is left out, since RWE option trading did not start before September 1990. 
least partly by the casual observation that international investors seem to prefer option listed stocks for investment purposes. The hedging opportunity created by the DTB apparently made listed stocks much more attractive to international investors who are responsible for a large fraction of German trading volume.

Another possible factor that might explain the diverging volatility evidence is a selection bias in the choice of stocks to be option listed. Skinner (1989) reports that stocks must have a minimum variance in order to be listed at an option exchange. If stock volatility is mean reverting and option introduction occurs at peak volatility levels, the variance decline in studies of the USmarket may therefore reflect the return to normal volatility levels. Evidence on the existence of mean reverting stock price volatility has been found by Merville and Pieptea (1989) who show that option implied volatility follows a mixed mean-reverting diffusion with noise process. Although Skinner argues that a selection bias is unlikely to affect his findings $\mathrm{Ma}$ and Rao (1986) indirectly support the selection bias argument by showing that relatively volatile stocks tend to become more stable after option listing while stable stocks tend to become more volatile. The DTB stocks were selected according to criteria such as size, industry, and market liquidity but not return volatility. Additionally, the stock selection for option listing took place some 18 months before the opening of trade. We can thus be confident that the German evidence is not affected by any selection bias.

As a final remark one might note that a rising volatility does of course not have welfare implications on its own. Even if risk averse investors suffer from increased volatility, welfare may nontheless increase if stock prices adjust faster to new information or by the introduction of new hedging opportunities created by the DTB.

\section{References}

[1] Bansal VK, Pruitt SW, Wei KCJ (1989) An empirical reexamination of the impact of CBOE option initiation on the volatility and trading volume of the underlying equities: 1973-1986. Financial Review 24:19-29

[2] Bauer RMM, Nieuwland FGM, Verschoor WFC (1994) German stock market dynamics. Empirical Economics 19:397-418

[3] Conrad J (1989) The price effect of option introduction. Journal of Finance 44:487-498

[4] Damodaran A, Lim J (1991) The effects of option listing on the underlying stocks' return processes. Journal of Banking and Finance 15:647-664

[5] Deutsche Bundesbank (1993) Monatsberichte der Deutschen Bundesbank. October

[6] Detemple J, Jorion P (1990) Option listing and stock returns. Journal of Banking and Finance 14:781-801

[7] DTB - Deutsche Terminbörse GmbH (1993) Annual Report

[8] Elfakhani S, Chaudhury M (1995) The volatility effect of option listing: Some Canadian evidence. The Quaterly Review of Economics and Finance 35:97-116 
[9] Grossman SJ (1988) An analysis of the implications for stock and futures price volatility of program trading and dynamic hedging strategies. Journal of Business 61:275-298

[10] Hardouvelis G (1988) Margin requirements and stock market volatility. Federal Reserve Bank of New York Quarterly

[11] Harris L (1989) S\&P 500 cash stock price volatilities. Journal of Finance 44:1155-1175

[12] Hayes SL, Tennenbaum ME (1979) The impact of listed options on the underlying shares. Financial Management 8:72-76

[13] Karpoff JM (1987) The relation between price changes and trading volume: A survey. Journal of Financial and Quantitative Analysis 22:109-126

[14] Klemkosky RC, Maness TS (1980) The impact of options on the underlying securities. Journal of Portfolio Management 7:12-18

[15] Ma CK, Rao RP (1986) Market characteristics, option trading and volatility of the underlying stock. In: Advances in futures and options research, vol. 1, Part A: 193-200

[16] Ma CK, Rao RP (1988) Information asymmetry and options trading. Financial Review 23: 39-51

[17] Merville LJ, Pieptea DR (1989) Stock-price volatility, mean-reverting diffusion, and noise. Journal of Financial Economics 24:193-214

[18] Nölkel D (1990) Die Deutsche Terminbörse: Bedeutung und Einfluß auf die Kassamärkte, Pfaffenweiler

[19] Runde R (1993) A note on the asymptotic distribution of the F-statistic for random variables with infinite variance. Statistics and Probability Letters 18:9-12

[20] Schlag C (1991) Der Einfluß der Deutschen Terminbörse auf Volatilität und Wertpapierrisiko am Frankfurter Aktienmarkt. Zeitschrift für Bankrecht und Bankwirtschaft 3:92-98

[21] Schmid F, Trede M (1996) Testing for first-order stochastic dominance: A new distributionfree test. The Statistician 45:371-380

[22] Schwert GW (1989) Why does stock market volatility change over time? Journal of Finance 44:1115-1153

[23] Skinner DJ (1989) Options markets and stock return volatility. Journal of Financial Economics $23: 61-78$

[24] Stein JC (1987) Informational externalities and welfare reducing speculation. Journal of Political Economy 95:1123-1145

[25] Stucki T, Wasserfallen W (1994) Stock and option markets: The Swiss evidence, Journal of Banking and Finance 18:881-893

[26] Trennepohl GL, Dukes WP (1979) CBOE options and stock volatility. Review of Business and Economic Research 18:36-48

[27] Whiteside MM, Dukes WP, Dunne PM (1983) Short term impact of option trading on the underlying securities. Journal of Financial Research 6:313-321 